\title{
16. LEGAL PLURALISM AND THE \\ PROBLEM OF IDENTITY
}

By: Professor Robert Hughes

\section{KEY TERMS AND PHRASES}

\section{Pluralism - legal}

The term covers various theories of law which hold that there can be many independent spheres of law, such as local or customary law, which do not require or depend upon the existence of a central state as the primary law making body in a society.

\section{Pluralism - political}

A body of theory which holds that the existence of groups and associations within society perform an essential function in any democratic society by mediating between the public arena of government and the individual citizen.

\section{Monistic state}

The idea, generally opposed by legal pluralists, that the state is the sole and final repository of legal and political authority within any society.

\section{Orthodoxy}

A body of theory, set of ideas or ideology which is either unchallenged and/or ordinarily accepted as an explanation for some phenomenon.

\section{Formalism}

In the legal context formalist theory conveys the idea that law consists essentially of abstract and general principles which are not dependent on any substantive principles such as those based on social norms and practices, customs and moral or ethical ideas including principles of justice.

\section{Ontology}

In philosophy, ontology is that area which concerns itself with questions of being; that is to say, with questions as to what things must assumed to exist and not exist. Most theories about social phenomena usually convey assumptions about what things the theorist takes to be the fundamental elements of society.

\section{Legal Postulates}

Basic propositions advanced by a particular theory of law. 


\section{INTRODUCTION}

In this chapter I will take up one aspect of the legal pluralist challenge to conventional views of law and legal institutions. My concern is primarily with the challenge to the unified conception of the state which many legal pluralists hold is pivotal to the orthodox theory of legal systems. The orthodox position (i.e. positivist jurisprudence) holds that the existence of a unified central or monistic state is necessary for the existence of law in the sense that law is logically antecedent to the state. One of the central concepts or principles underlying this orthodox conception of a state is that of a unified identity. In this chapter I am suggesting that this concept is fundamentally misconceived for a variety of reasons. I will suggest an alternative understanding of identity and outline the consequences of adopting such an alternative in our understanding of the state.

The challenge of legal pluralism is made difficult to assess because of the absence of a coherent body of legal pluralist theory. So far as the state is concerned legal pluralism often appears as a critique of the state rather than as a theory pretending to offer any alternative view. Its business seems to be incomplete in some ways. There are also many versions of pluralism which lead in possibly different directions. The view I wish to put forward, nevertheless, is that legal pluralism's challenge is to be taken seriously and that we ought to attempt to accommodate it. I will argue that the monistic conception of the state is, regardless of its orthodoxy, a misconception. What the state presupposes is not some all-embracing unity as such. What it should be taken to presuppose is, rather, an identity; but an identity understood in a particular way that is consistent with the idea of the state as a substantive association rather than as an abstract or formal corporate institution. The South Pacific experience of 'small' states simply reinforces our need to recast our fundamental conceptions of the state in this way. In larger and more complex 'Western' societies we often lose sight of the fact that a state is basically composed of human individuals who are associated in various ways. The tendency has thus long been to conceive of the state in wholly abstract formal terms, such as appears in corporate theories of the state. In South Pacific states, given their size and the relative familiarity involved in social relations between their citizens, this abstract conception seems immediately inappropriate.

\section{LEGAL PLURALISM - CLAIMS AND CHALLENGES}

We should initially look at some of the claims of legal pluralism in more detail in order to set the context of the following discussion. What is legal pluralism? Hooker defined legal pluralism as that which "refers to the situation where two or more laws interact." Griffiths defined it as the presence in a social field of more than one legal order. ${ }^{2}$ For Chiba legal pluralism is that body of theory which recognises that the total context in which law operates within a legal system consists of a plurality of different culturally determined 'layers' of practice which might consist of official laws, unofficial laws and legal postulates. These cannot be wholly controlled by the central state nor unified under its authority. In fact, these layers continue to develop independently of the state and its institutions. However, these different systems of laws can and do interact with 
one another. This seems not to be a necessary interaction but a possible one only. The interaction is sometimes harmonious and sometimes not. ${ }^{3}$

Legal pluralism, in its advocacy of what is sometimes called the 'local law', 'customary law' or 'the people's law', presents us with conceptions of law. Law, so it is claimed, is a culturally relative concept and in many cultures there are customs, practices, conventions and quasi-legal rules which perform a function similar to those of law elsewhere. This can be so notwithstanding the absence within those environments of a state with a concomitant monopoly on power and law-making authority. ${ }^{4}$

Thus legal pluralism clearly challenges one of the precious themes of standard legal theory; namely, that there must be a state understood as a centralised legal institution. ${ }^{5}$ This centralised institution is the modern unified nation state that has as its primary function that of law-making or legislating. ${ }^{6}$ This rule- or law- making function is allegedly paramount and supercedes the authority of any other form of law, including judge made law. As this supreme legislative function is usually one of parliament there is parliamentary sovereignty. As parliament is a supposedly representative body comprised of members elected by the people the state, and hence law, might be thought to be democratic. From a legal pluralist perspective however, nation states are increasingly challenged by the existence of cultural and social diversity which they find within themselves. ${ }^{7}$ The orthodox theoretical articulation of the nature of a state in fact implies that there is a large gap between the state, as such, and culture. This gap is especially evident in so far as this understanding of the state cannot theoretically accommodate multicultural and multi-religious content.

According to legal pluralists, one consequence of this sovereignty principle is that it devalues custom, tradition and culture. It both elevates itself at the expense of culture and values and eschews any serious attempt to understand law or legal institutions in light of these 'non-rational' and contingent historical principles. ${ }^{8}$ Custom, on the centralist view, is perceived as that which is typical of societies that are relatively undeveloped or under-developed. Custom based societies are those that have insufficiently progressed towards modernity. Thus the orthodoxy of state-centralism is revealed as substantially biased in favour of modern constitutional principles, which are in turn supported by a range of assumptions about modern culture as opposed to traditional or 'primitive' culture and custom.'

There are other associated orthodoxies occasionally challenged by legal pluralists, expressly or impliedly. One of them concerns the central importance of law itself. For example, it is sometimes contended by pluralists that it is only in European culture that the primary principle of social and political order is taken to be law in the sense of apparently value-neutral, rationally justifiable and publicly created rules or principles. Other cultures might have 'law', or something like the Western sense of it but it is not all that important either in the production of social order or in conflict resolution. ${ }^{10}$ In another way, legal pluralism has presented an alternative theoretical perspective to challenge the legal positivist conception of the relationship between law and culture and law and society Whilst positivism eschews any meaningful or 
logical relationship between them, legal pluralists purport to establish quite the reverse.

\section{Different concepts of legal pluralism}

\section{'Classical' and 'new' legal pluralism}

Legal pluralism developed distinctly as a "law from the outside" perspective ${ }^{11}$ mainly through legal sociologists and anthropologists who were studying traditional or stateless societies. They were often confronted with what appeared to be quasi-legal rules, practices and orders that seemed to warrant some consideration as law within these societies. ${ }^{12}$ These so called 'classical legal pluralism' proponents asked us to suspend belief in our Eurocentric concepts of law and to entertain the claim that, in some cultures, custom, or at least some part of it, could be regarded as law. One theme, perhaps, was that we should restrain our Western philosophical tendency to universalise our own concepts - legal and otherwise - and accept some form of cultural relativism.

The focus of this classical legal pluralism was on the relationship between introduced legal systems and custom. ${ }^{13}$ These different spheres aligned, and perhaps still do align, themselves readily with the politics of modernisation and development on the one hand, and the defence of traditional society and culture on the other. Sometimes the respective poles indicate alignments on issues of colonising values versus those of selfdetermination. Yet, ironically, the distinction, largely unacknowledged in classical legal positivism itself, between introduced and customary law was largely the creation of colonisers themselves, and custom mostly assumed the characteristic of reinvention tainted by the intervening colonial experience. The institutions raised to defend custom and tradition were often those created by the colonial government to achieve nothing more than administrative convenience. ${ }^{14}$ The body of custom itself was affected by its interaction with colonial law, such that it could not be taken as a preexisting body of customs or practices.

The body of Pacific jurisprudence that is concerned with the relationship between introduced and customary law largely fits within the tradition of classical legal positivism. We can also see the opposing tensions of modernisation and tradition within politics in the Pacific. The ironic nature of the custom/introduced law dichotomy is, perhaps, not as thoroughly examined, particularly as it weakens the foundations of the policies of tradition as compared to modernsation.

Some legal pluralists have since turned their attention to European legal systems, arguing that even those systems are pluralistic in important respects. Whilst legal pluralism was once an approach that was distinctively focused on questions as to the operation of law in post-colonial societies that is no longer the case. The theoretical approach has inspired some renewed thinking about the nature of legal systems in Western countries such as those of Europe and the United States. Writers such as Merry and Van den Bergh have seen pluralistic patterns operating in various industrialised societies. ${ }^{15}$ This is sometimes called 'new legal pluralism.' Turned back 
on itself legal pluralism has seemed a suitable platform from which to investigate the plurality that consists in various non-state forms of social order existing within the larger and enveloping unity of the state. It has purported to reveal a plurality of legal orders which operate within late capitalist societies. Merry sees the new legal pluralism as having shifted from the classical problematic which was with the mutual relationship and interaction between separate spheres of order such as introduced/official law and custom or non-official law. It has become concerned with the relationship between the official legal system and "other forms of ordering that connect with but are in some ways separate and dependent on it" ${ }^{16}$ It is concerned with a complex network of relationships which exist within and between overlapping groups and subordinate orders which also interact within the same overarching structure. Thus "this perspective sees plural forms of ordering as participating in the same social field."

The new legal pluralism seeks to direct us away from the frequently assumed theoretical dualities of state and society, law and non-law, official and unofficial law, public and private towards more multifaceted terrain. One of the questions it compels us to ask is whether there can be a pluralistic logic applied to conceptions of European law and state which would displace that conventional logic which demands a mere unity both of the sovereign state and of the legal system. ${ }^{18}$ But the consequence of new legal pluralism, ironic in some ways, is to eliminate some of the fundamental differences in cross-cultural perception. If all societies have pluralistic structures have we not, via the all-embracing techniques of social science, produced a new universal or modernist understanding of society and state?

\section{Legal pluralism, political pluralism and political theory}

In exaining different concepts of legal pluralism it should be noted that it cannot be viewed, historically at least, to be a product of what is known as political pluralism, which developed particularly in the United States and is characterised by minority and interest group politics. Political pluralism is a theory which promoted the role of such groups as a vital one in a democratic society. This is particularly because these groups or associations provided, firstly, an opportunity for some degree of participation by citizens in larger social purposes and, secondly, because they perform a mediating function between the public and private spheres in society. Legal pluralism, it is sometimes said, has had, and needs little or no input from, this particular movement. Baxsi, for example, suggested:

I believe that although liberal doctrine and dogma of interest group pluralism has run aground, there is no need to import this crisis into the domain of legal pluralism. While thinking on legal pluralism has been influenced here and there by liberal doctrine, literature on legal pluralism has, by and large, arisen from the sociology of law (including legal anthropologists) and comparative lawyers. No leading liberal theorist has bothered much about legal pluralism let alone with the relative autonomy of law in an analysis of the state... Legal pluralism does make 
certain assumptions about the nature of the state and civil society, but these assumptions are rarely tied to a specific version of interest group pluralism. ${ }^{19}$

However I think it is also a fallacy to assume that legal pluralism can or need pretend to be anything other than a form of political theory. Discourse and argument as to the nature and role of the state has long been taken as characteristic of political theory. Legal pluralist argument, whatever use it might have had for comparative law, seems fundamentally to challenge our thinking about the state, if also its relationship to law, so is a branch of political theory. ${ }^{20}$

\section{Juridical and social science and strong and weak versions of legal pluralism}

Aligned to the classical and the new versions of legal pluralism, as mentioned above, there is the juridical version and the social science version. The juridical version is that which is concerned, as Griffiths suggested, with the drawing of links between parallel systems in the context of the overall system. Law and the state provide a kind of coordinating role in respect of diverse sub-systems of law. The social science version is more concerned with revealing the content of the complex web of relationships which exist between orders whilst admitting that there might be some more general linkage between them, for example, in terms of law.

Along the same lines there is sometimes said to be a weak version and a strong version of legal pluralism. Weak legal pluralism would hold that there can be 'parallel systems' of law; primarily state law and non-state law, introduced law and customary law. It endorses the recognition of alternative systems within a state, although they are systems which are not dependent on the state as such for their authority. The strong version, on the other hand, would hold that even the distinction between law and non-law postulated by state centralism itself is, in fact, socially constituted or constructed. Clearly the category of the social assumes a primary force here, which indicates also the sociological bias in the analysis. It insists on a 'mutually constitutive' nature of law and society. ${ }^{21}$ Such a view usually places considerable emphasis on the plurality or diversity of distinct legal orders existing independently of the state. The disunity of the 'system' in general leads readily to the conclusion that law can and does exist without the need for a state at all. Hence, so it is claimed, the state cannot achieve the basic unifying function which orthodox theories attribute to it.

\section{Legal pluralism and polycentricity}

It is usual to differentiate legal pluralism from legal polycentricity, although the basis for the differentiation is often confused. Legal pluralism describes and accepts multiple legal orders within some more general community or association and proceeds to consider the ways in which these might intersect. At the national level, this community is obviously a state, but in some cases this is extended to the international or global context or community as well. Polycentricity focuses rather on the law itself. It seeks to indicate that law manifests something other than the unity and coherence which it is often assumed to have. Rather than achieving stability through this alleged unifying function law can be shown to contain an inherent 
elements of inconsistency, disunity and, therefore, instability. Others in this vein refer, more specifically, to the factor of fragmentation and to the lack of any cohesive moral foundation for law. ${ }^{22}$ If legal pluralism is a view of the legal order from without then polycentricity is a view from within, which seems to suggest that perhaps it is law or the legal Weltanschaunng (world view) which accounts for the plurality of the world. ${ }^{23}$ Yet the two are sometimes difficult to disentangle.

\section{Legal Pluralism - Comprehensive Theory or Marginal Critique?}

There are now several different dimensions or contexts of legal pluralist argument along with a shift in the focus of attention. There is that which is dualistic and has largely focused on the coexistence of local decentralised systems of law and central state based law within a given system. But there is also that which shifts attention to another context, which is the global and seemingly stateless context. This is what Chiba has termed "legal pluralism in triple structure". ${ }^{24}$ This structure assumes the dualistic structure of operation of legal pluralism but extends beyond it. In this context Teubner, for example, argues:

Global law can only be adequately explained by a theory of legal pluralism which has recently successfully turned from the law of colonial societies to the laws of diverse ethnic, cultural and religious communities in modern nation-states. It needs to make another turn - from groups to discourses. It should focus its attention on a new body of law that emerges from various globalization processes to multiple sectors of civil society independently of the laws of nation states. ${ }^{25}$

It could be thought that legal pluralism is not in any particular need of any theoretical perspective to do its work. Perhaps many legal pluralists merely accept that different peoples have different senses of law, setting out from there to understand what that sense of law is. This lack of theoretical perspective is a possible deficiency of legal pluralism as acknowledged, for example, by Griffiths. There is a lack of clear definition of just what pluralism entails and in particular what it propounds as an alternative to the legal centrism that it sets out to correct. ${ }^{26}$ But perhaps this is not a problem. Bergh suggests instead some kind of Hegelean solution to the lack of a single theoretical perspective. The legal pluralist position would thus be seen not as one of adopting a pluralistic logic of categories of laws which would potentially and, perhaps inevitably, lead to conflict. Pluralism is rather to be seen as a process that develops in and over time. ${ }^{27}$ It is not a static situation or set of interrelated categories but a complex pattern of interaction taking place constantly. ${ }^{28}$

In summary, legal pluralism claims to reveal the operation of a number of legal orders within a society. Those legal orders are administered in several sets of institutions. ${ }^{29}$ This implies a system of complex interactions within a legal system, the notion of a 'system' here being taken in a rather loose or open sense. Sometimes the parts of the system interact closely with one another and sometimes they do not. As one writer puts it "law in modern society is plural rather than monolithic,... it is private as well as public in character and... the national (public, official) legal system is often a secondary rather than a focus of regulation." ${ }^{30}$ In principle, such a conception of a 
legal system has a ring of familiarity to it to most who have engaged in the practice of law. From such a perspective, the idea that there is any coherent unifying principle operating in the legal system would be the product of idle fancy. At times there appear connections between areas of law but there are also substantial gaps between areas of law and between law and practice. At times, usually during periods of judicial radicalism, the courts appear to assume a reductionist stance proposing that there are deep connections between principles in tort, contract and equity, for example. But it has generally defied jurisprudence to show that there is uniformity (rather than equivalence) across the different sub-domains of a legal system. From the practical standpoint the legal system would be better conceived in terms of diverse practices which sometimes overlap and interact and sometimes they do not. Discrete groups or sub-groups do operate even within all legal systems. Sometimes they stand in direct connection the state, and sometimes independent of it. The division between groups and also between state law and local law cannot be cast in rigid terms or as harsh conceptual divisions. ${ }^{31}$ It is the complicated interaction of the legal system as such which renders the term 'pluralism' appropriate.

Despite this, within so-called Western societies, legal pluralism has not developed much beyond a marginal critique. The recognition of plurality of legal orders as an empirical phenomenon can perhaps be dismissed as an unfortunate complexity another case of facts not being allowed to get in the way of a good theory. Legal pluralism runs foul of the dominant view that different legal systems cannot co-exist within the structure of a sovereign state without challenging the continuing authority and legitimacy of the state. Moreover, from an international perspective, legal pluralism might seem to erode the claimed need for absolute independence of a nation state by weakening the inner unitary core of the state. The claim to a plurality of legal orders, in other words, appears contrary to the idea that the law should derive its authority ultimately from a single source. ${ }^{32}$ Furthermore, in the originally fertile ground of legal pluralist research, the so-called traditional societies themselves, there seems a strengthening of state centralism as new governing elites seek out rapid development, international financing, structural reform and rapid assimilation to the liberal capitalist model of the state. All of this seems to imply a strengthening of legal positivism within these societies,$^{33}$ although not without resistance form other sectors within the society. ${ }^{34}$ Thus the actual tendency of many such societies, especially after independence, has been towards a positivist rather than a legal pluralist paradigm.

\section{Legal positivism and the Pacific}

In the Pacific context positivism is that which reinforces the supremacy of introduced law and systems of government that are part of the colonial heritage. They are no longer colonial societies but they are not traditional either. Colonialism has left behind legal/political systems in which elements of custom and modernity are intermingled in an ambivalent and uncertain relationship with a central state system. Nowhere is custom exactly pre-colonial custom and, as is common in 'new' states post-independence, traditions need to be invented and reinvented to forge some kind 
of community out of the colonial residue. Legal pluralists have not been able to agree themselves on the future of this relationship between introduced law and custom. Some in fact have argued that custom will inevitably be eliminated by introduced law. ${ }^{35}$ The co-existence of these two produces in these societies a thorough-going systemic confusion of authority. Legal pluralism plays to some extent, and perhaps originally, on connections between custom or tradition and self-determination or independence. ${ }^{36}$ Thus the tension between custom and the introduced legal system is represented as that between independence and some form of lingering cultural imperialism.

Inevitably, however, there is ambivalence in the Pacific region about playing this song of independence to the end. On the international political scene it is still important for the small Pacific countries to engage in the statehood game so as to maintain recognition as states. This has strategic significance not only in terms of internationally sourced funding for aid and development. It also impacts directly on the content and structure of internal politics. Introduced government systems or central state structures lend themselves to a certain sort of politics. They provide a playing field suited to certain sorts of players - particularly educated and nontraditional elites - who play according to a different set of rules. Those who are empowered in this way are those who frequently preach the gospel of custom and tradition whilst in practice ignoring it. Thus it becomes less likely that the introduced legal system will be subjected to modification or change or that the tension between custom and the introduced legal system will be resolved. One thing that the Pacific countries do make obvious - perhaps as a result of their size — is the fact that pluralism within these states has a certain explanatory power. They are small societies but they are highly complex and diverse in their composition. Thus the so-called official view of traditional jurisprudence that has tended to apprehend political societies or states in terms of their apprehended unity and uniformity seems remarkably deficient in this environment.

\section{THE TRADITIONAL CONCEPT OF THE STATE}

We have seen that legal pluralism rejects the concept of a monolithic state. This can be contrasted with the traditional jurisprudential view of the modern state, which sets out to justify the idea of the modern state which, in turn, finds as its key principle, historically and theoretically, the principle of sovereignty. ${ }^{37}$ In modernist terms sovereignty embodies certain key ideas, not the least of which is its essential unity or indivisibility. It must do, so the argument goes, because now sovereignty has the sense of absolute and final political and legal authority.

This concept of the modern state is based on the works of those such as Hobbes, Locke and Rousseau. It is a formal or imaginative conception which makes certain assumptions about the necessary uniformity of human nature as a defining condition of membership or citizenship. This is only possible if we treat a state as a formal association, and define the individuals who comprise it in terms that are themselves essentially formal. 
The essential unity of the sovereign state is clearly enough expressed, for example, in Hobbes' corporate view of civil or political association; a theory which clearly involves borrowings from Cicero and the later medieval jurists. ${ }^{38}$ Faced with the fact of impenetrable human diversity, the answer of theorists such as Hobbes was to appeal to artifice rather than nature, and more particularly to personation theory provided by the classical jurists.

The natural unity of humanity was a thesis of Platonically inspired natural law theory. It was rejected by Hobbes on the basis variously of its absurd, unscientific and irrational metaphysical doctrines. ${ }^{39}$ To Hobbes, the many can become one if they are united in an artificial sovereign persona which is the product of their own covenant and to which they assign power over themselves. As an artificial person the sovereign body is a kind of Hobbesean individual writ large, its mortal imperfections perfected in the abstract in light of reason and imagination. It has a kind of completeness of power which is also the final and ultimate source of all political legitimacy. Unity is possible for such a being because it is both separate from and above the diversity of natural (or 'private') human existence in the so-called State of Nature. The primary function of this 'thing' is, moreover, to legislate. ${ }^{40}$

\section{Modern constitutionalism}

The fundamentals of Hobbes' political theory provide the platform for modern constitutionalism. In his book Strange Multiplicities ${ }^{41}$ James Tully draws out what he takes to be the seven conventions of modern constitutionalist doctrine. This doctrine, he claims, constitutes an orthodoxy which is adhered to in varying ways by contemporary liberals, nationalists and communitarians. Each of these three groups in fact have slightly different but consistent enough versions of popular sovereignty. It is these seven features which together enabled adherents of modern constitutional theory to suppress arguments based on ancient constitutionalist principles including tradition and custom. They continue to exclude the voice of diverse minority interests and intercultural groups from constitutionalist argument. But further they supported the claim that the principles thus developed are of universal validity, thus diverting attention away from intercultural as well as regional diversity on the global scale. These seven conventions are as follows ${ }^{42}$ :

1. There is adherence to the basic notion of sovereignty as a modern principle of statehood.

2. The modern constitution is defined in contrast to ancient or historically earlier constitutional types which are sometimes treated as 'earlier' and as belonging in a lower phase of historical development. It also sets up a distinction between that which is distinctly European, and that which is not. Ancient constitutions are also most often treated as implying irregularity or disorder. The traditional and the customary become something pre-modern but more significantly also primitive, underdeveloped, incompletely formed. Hence there is what Tully calls an imperial element in the argument. 
3. There is a contrast between the modern constitution with its features of unity, uniformity and order, and the ancient constitution(s) which has features of disunity, differentiation, plurality, multiplicity, disorder.

4. There is the recognition of custom within a general theory of progress. It appears as a lower phase of historical development and, more especially as something which is overtaken or rendered irrelevant by progress.

5. Modern constitutionalism becomes identified with respect to a particular set of European political principles as essential features of what was sometimes called a 'republican constitution'. This includes the likes of rule of law, separation of powers, representative government, equal citizenship with fundamental rights and a distinctive public realm.

6. The sixth convention is one that he takes to have come especially to the fore since the French and American revolutions. This is that:

a constitutional state possesses an individual identity as a 'nation', an imaginary community to which all nationals belong and in which they enjoy equal dignity as citizens. Although the nation is interpreted differently in each society... it engenders a sense of belonging and allegiance by means of the nation's individual name, national historical narrative and public symbols. By naming the constitutional association and giving it a historical narrative, the nation and its citizens, who take on its name when they become members, possess a corporate identity or personality. From Pufendorf onward, this corporate identity of nation and nationals in a state is seen as necessary to the unity of a modern constitutional association. ${ }^{43}$

7. The final convention is that which aligns or assimilates modern constitutions and democracy. As he puts it, "the modern constitution comes into being at some founding moment - and stands behind and provides the rules - for democratic politics." 44 The modern constitution appears as a precondition rather than a part of democratic politics. It lays the ground and prescribes the domain of debate on democratic politics at the same time excluding the classical dimensions of democratic debate.

Tully acknowledges in fact that legal pluralists are those who have challenged this uniformity supposed to exist in modern states conceived under the dominant rhetoric of modern constitutionalism. It is the rhetoric of modern constitutionalism that devalues alternative conceptions of a state based on principles which acknowledge and respect diversity just as the principles of modernity purport rationally to exclude the likes of custom, traditional and the diversity which this entails both internally and globally. It is modernity and the logic of both universalism and uniformity that drives this rhetoric, which purports in a wider global context to devalue and debase cultural and social diversity. 


\section{Modern consitutionalism and the state in the Pacific}

We can see the impact of the need for unity in the concept of the modern state in independence movements in the Pacific. This concept shaped the political imagination and the resultant form of the emerging nations. For example, in Vanuatu the politics of nationalism were expressed in 1971 by the newly formed New Hebrides National Party. One of its first public statements began:

Our aims in forming a National Party are to preserve the New Hebridean people; their culture and their ways of life are in danger of large scale settlement by Europeans. ${ }^{45}$

Nationhood was seen as being the end goal of decolonisation, with the national purpose being to protect and project the national cultural past of the New Hebridean people. The cultural underpinnings of nationhood, with its ideological insistence upon cultural homogeneity, inevitably affected the political imagination. Despite the fact that the group of islands that now make up Vanuatu did not form a single entity until they were defined as the New Hebrides by colonisers, a single New Hebridean people $^{46}$ and New Hebridean culture became the justification for the creation of Vanuatu. ${ }^{47}$

Also if we look at the current constitutions of the Pacific states themselves we will see the familiar proclamations of the unity, common destiny, common citizenship and heritage of the people; in all an assumed identity of the people under the adopted constitutional frameworks. They are complete with conventional proclamations of the rule of law, the common possession of fundamental rights and freedoms and equality of all before the law. Almost without exception these documents are masterpieces of liberal design reinforcing the various tenets of modern constitutionalism as Tully has described it. The central legal authority of the state is clearly established. The role of custom is recognised but generally, with the possible exception of Vanuatu in relation to land ownership, is subordinated to the central authority of the state. ${ }^{48}$

Yet the assumed identity constructed or at least assumed by these constitutions has been shown by recent events to be an unstable one. The relationship between modern constitutional theory and actual practice in the Pacific is tenuous. The civil war in Solomon Islands from 2000 onwards, and the events following the attempted coup in Fiji Islands in May 2000 have, for one thing, shown that assumptions about the underlying unity of a people at the national level are frequently misplaced. The forces of fragmentation and internal division were, if anything, shown to be much potent than any reading of the the constitutions themselves would have suggested.

\section{THE PROBLEM OF IDENTITY}

It is the sixth convention in Tully's analysis above which is of interest. He talks of a convention within the doctrine modern constitutionalism which is that of identity or at least a particular sense of it. The notion of identity that Tully is referring to here is what he calls corporate identity, but it might equally be called formal, nominalistic, artificial or abstract identity. It is a product largely of elevation of the writings of 
Hobbes, Locke and Hume on identity into something of an orthodoxy amongst liberal philosophers. ${ }^{49}$ This is a notion of identity as a simple unity in the sense I have already mentioned.

Tully seeks to solve the problem of a unitary concept of identity by developing a notion of identity using the theoretical perspectives of Wittgenstein, postmodernism, post-structuralism, interculturalism and feminism. He purports to reconstruct the idea of identity such that it is a product of, and contains difference. That is to say, it is a sense of identity that does not involve self-reflexive or essentialist notions of identity. Such a concept of identity allows for a state which can accomodate intercultural ideas, ideas of cultural diversity and so on. I do not disagree with that conclusion but I think there are other ways of proceeding. The major points I wish to make are as follows:

First, modernist authors from Hobbes and Locke onwards have simply misrepresented the concept of identity as if it were, and could only logically be, a principle implying simple numerical unity. These writers were, for their own political ends, keen to reject the metaphysics of both Neoplatonism, Catholicism and natural law along with the challenges to secular political authority which these seemed to entailed. Thus they rejected, or at least redefined, what was one of the key defining principles of it; namely, the principle of identity taken in a properly collectivist sense..$^{50}$

Second, this misconception of identity renders any conception of an association or a collectivity, human or otherwise, not so much impossible, but highly abstract. It is a creation of the philosophical imagination or of grand artifice because it is only in the imagination or in abstract thought that a corporate identity achieving such a unity could be conjured up out of the diversity of practical existence. Treated in this way identity could only be employed in our understanding of a state as if those which it unites are treated as fundamentally the same in some respect or other. To Hobbes, and perhaps correctly, this would be impossible with respect to natural individuals. But these individuals also assume a certain conformity if we attribute to each individual by virtue of the covenant a formal persona as citizens which appropriately affects their membership but also their subjection of the artificial corporate persona. But the corporate unity is, as I have indicated, a reflection of the simple atomic or numerical unity of the individual. It does not carry with it the multiplicity of the 'state of nature'. Nor does it carry any taint of the multiplicity of individual membership. It transcends even that because it is an essential unity. Thus as we say in modern corporate theory, according to the separate identity doctrine: it has an identity (i.e. a juristic status) distinct from its individual members or any aggregation of them.

Thirdly, there is another way of understanding identity that is not exclusive of diversity or difference at all. Such an employment of the concept is quite legitimate from an historical point of view as also from a logical point of view. It is that sense of identity which I suggest is more appropriate to our understanding of a state. 


\section{Concepts of Identity}

I have elsewhere explored the relationship between identity and politics and implicitly, perhaps, the relationship between identity and the state. ${ }^{51}$ There are many who would think that the connection between identity and political discourse is a recent one. It is common enough now to talk of 'identity politics' as a certain sort of political debate occurring particularly in the U.S.A. in the 1960s and 1970s as, for example, a politics of gay identity, race identity, ethnic identity and so on.

It is apparent that this recent theme of 'identity politics' has itself come to an end. One of the reasons for that is that the concept of identity that it employed is that of a simple or numerical unity or oneness. Given this, the suggestion appeared to be that identities such as racial, feminine or ethnic could be reduced to some seamless or pure conceptual base. This search for a numerical, finally specific, essentialist notion of identity was inevitably a failure, because it was found that within such identity categories there were considerable and significant differences to be accounted for. Thus it is an odd story. That which was alleged in itself to capture a definitive essence of something and thereby differentiate itself from the rest, merely collapsed. What it sought was impossible either to achieve or to sustain because an identity concept such as this, being one that admits no difference, diversity or change, is an impoverished one. ${ }^{52}$

But the connection between identity and politics is much longer and the potential for this concept far more considerable than these undertakings might indicate. Are there richer alternatives to the concept of identity? Here, maybe, we can look to Hegel. Identity has a seemingly peculiar and difficult sense in Hegel's conception of the dialectic. The dialectical method is integral to Hegel's understanding of philosophy, or the so-called philosophy of the 'Absolute Idea'. Thus it is integral also to Hegel's philosophy of the state as expressed in the Philosophy of Right..53 The dialectic is a process or movement from unity to diversity to a higher phase of unity. All might be change in some sense but it is an orderly, logical process of change. Thus it is more appropriately a sense of development. It is that higher phase, which is a unity of the diversity which can gone before it ${ }^{54}$ which is specifically called "identity" by Hegel.

Many have set out to ridicule Hegel's concept of identity as if concepts such as unityin-diversity, unity-in-difference or sameness-through-change entail a basic contradiction in terms. Identity, Hegel's critics hold, means a numerical unity (hence exactly the same, oneness). Thus it can hardly be something found in, or compatible with, difference. But this is clearly not what Hegel was arguing at all, as far as I can tell. He was arguing that identity, at its simplest, is that process whereby thought moves from a point of unity to a point of differentiation from that unity, and thence to a higher, fuller unity. Identity is precisely the outcome of this process and necessarily implicit in all of the stages of this process. As a process it incorporates the moments of unity and difference. Furthermore, these critics simply fail to understand that the tradition of understanding that Hegel was drawing on here is a tradition in which identity is not understood as a principle of simple unity, individuation or oneness. It is a tradition which builds on Aristotle and Neoplatonism (Christian and otherwise, classical and medieval) as much as Leibniz, Fichte, Kant and Schelling. 
True, it is a tradition which can be understood in terms of its tendency towards unitary metaphysics. But another fruitful way of looking at it is that it is a tradition which attempts to balance or mediate the two sides of unity and diversity; sameness and difference.

\section{Two Senses of Identity?}

If we take an overview, we can say that there have been two differences of meaning assigned to the concept of identity. There is one which derives from Hobbes and Locke which treat identity as importing a type of simply mathematical idea unity i.e. oneness. There is the other, older, philosophical tradition in which identity is treated as that sense of unity that persists amidst difference. It is a unity-in-diversity in the sense in which we might speak of any form of human association as a form of unityin-diversity, a unity of different individuals.

\section{IDENTITY AND THE STATE}

If we are to take identity in this alternative sense and apply it to the understanding of states where does it lead us? Taking identity as a unity-in-diversity means that we can, in some more reasonable way, retain the sense that the state is an association of individual human beings. In the case of small states such as those of the Pacific this original sense of a state as a 'polis' might be more obvious than in larger 'developed' countries where formalism and abstraction have reached special heights, possibly as a reaction to complexity. But formalism is neither an inevitability nor a necessity. Our rethinking of identity in relation to states will lead us towards a possible resolution of the real problem posed by legal pluralism. This is not that of recognition of plurality in the face of the omnipresent unity of the state. It is that of finding some degree of balance between plurality and unity. The problems in Fiji Islands and Solomon Islands adverted to above are, I think, indicative of the need to address these issues, rather than seeking solutions within the framework of existing constitutional structures.

Let me sketch out some ways in which a balance between plurality and unity might be achieved. I will have to consider first the notion of association and, second, what identity in this revised sense might bring to it. Third, I will consider the idea of culture which I think is tied up with identity issues. Finally I will comment on the role of law within a state thus reconsidered.

All associations are primarily unities of diverse things or, to be more specific, unities, combinations, collectivities (however we prefer to put it) of diverse human individuals. The very idea of individuality implies, as I have said, an extreme of diversity and multiplicity. Individuals are allegedly unique and this clearly implies diversity. Hence where I am asserting that identity can be attributed to a state, and that it is a far more basic or workable way of conceiving of a state, I am suggesting that it properly captures the sense of the state as an association - a unity of diverse things. I am also asserting that this diversity is such that it might consist of individuals certainly, but also sub-associations of individuals in a wide and perhaps indeterminate 
array or relationships. In other words, we might prefer to think of states as associations of associations and of individuals, given the manifold ways in which human beings conduct themselves.

However that might be, we are still engaged here at a level of formal abstraction. An association is a unity-in-diversity which traditionally lawyers have been prepared to conceive of themselves, making clear distinctions between incorporated bodies and other forms of association. These associations are identities which are not distinct from the aggregates which compose them. But implied in this notion of unity-in-diversity is also the fact that what we are talking about is a systematisation of human conduct and experience $^{55}$ which, in some sense, brings together form and content. We need to consider how this might be so. The way forward here is in terms of the fact that identity is a relational principle. It asserts a relationship between (different) things.

Once this is understood we can proceed to the second point. This is that identity does not merely assert an association. It asserts association in some respect or other. Thus it asserts association by virtue of something that is held in common - some characteristic of sameness that is held by those who are associated. This is how unity is achieved and how the identity as a relational concept is to be grasped as identity with respect to a particular something or other. This is basic to the sense of identity I am seeking to articulate. In common parlance the identity of something is answerable by reference to the acknowledgement that it is something of a certain sort or type which it shares with other things. This is in large part why idealist philosophers constantly refer to identity as asserting a qualitative, rather than a numerical, unity. Identity is identity in respect of some common or shared characteristic or feature.

One can perhaps assume that things can be associated by chance or associated simply by being somewhere - a chance conjunction. One can also assume that there can be simple associations as a matter of principle. But on closer analysis even these things tend to be associated by virtue of some common or shared characteristic such as being in the same place, or being together at the same time or being human. Associations of human beings are meaningful, though not always purposeful, associations. They persist perhaps because they are attributed meaning by those who are associated even if the original circumstance of the association might have been one of chance or choice.

Third, it is this characteristic of being associated in a certain respect that brings out a connection between culture and identity. Culture consists of shared ideas or beliefs which are, in other words, held in common. Commonness is closely related to community. Culture is a community of ideas, beliefs and so on. These go to establish the content of identity. Whilst there is some conjecture about the possibility of natural identities in political associations I think that it is much more sensible to admit that all political identities are composed by human thought out of historical practices. Whether they actually represent human practices is quite another question. But what sort of identity is this? The content of such identity is cultural constructs which are created, challenged, adjusted and recreated. The whole idea of attempting to build political associations as if they were logical extensions of families and other 
allegedly natural forms of association is one which is dead and buried if indeed it ever were viable. Liberal theory has had its moment in putting this idea to rest.

The sense of identity here does not transcend culture because identity in the sense in which I am employing it has the characteristic of immanence. Immanence implies being contained within and confined by some more general context. Thus we can say that this cultural identity is indeed a diverse unity. Identity is embedded in culture. The form is determined within and by the content. It is identity which changes with the culture itself. It has the feature of relative continuity. It is persistent but it is not permanent. In the first place we must acknowledge the fact that identities vary considerably from one place and from one association to another. The variance is cultural. Additionally ideas both persist and are transmissible over time regardless of the comings and going of the generations or those who from time to time comprise the substance of an association.

It is primarily ideational culture understood as a community of shared ideas, beliefs and opinions that both provides and preserves the identity of the state. ${ }^{56}$ It is culture that transcends the individual experience of those who are the variety of associations within a state and indeed constitutive of the state itself, without destroying or denying them. We can say here that identity manifests a certain sameness but not sameness in any rigid or static sense. And it is certainly not sameness per se whatever that might be. Without a sustainable identity in that sense, the structure of a state and the prospects of its continuance are poor. Without any such identity the putative state and its institutions lack legitimacy.

It appears to me that cultural identity must exist to some reasonable degree before one can even begin to acknowledge the constitutional viability of a country. Without that underlying system or pattern of commonness or community then unity in any sense is impossible. Individual, ethnic and other forms of diversity are basic within the overarching identity of a state and play a vital role in the construction of the sustaining cultural identity. But at some point or other they could, if unrestrained, cause it to fragment.

How are we to treat law in such a scenario? Law is a set or a system of relatively abstract system of ideas. It is, I think, merely a subdivision or an aspect of a culture. This fact accompanied with the role of language in law lends itself directly to analysis in terms of culture. As a system of ideas law is very 'loosely' systematised. Its unity as a system is weak. This is because it the product of a history of abstractions from practice without any unifying or guiding logic and without clearly established axioms or assumptions from which to generate rules or formulae. Law is not like a logical system because it is affected by practice. It can never be the whole of culture even though in some respects it often pretends to function as if the abstractions it contains are somehow were representative or symbolic of the culture which surrounds and contains it. Legal culture captures the mutual and sometimes confused relationship according to which law is affected by and in turn affects culture. It is because of this mutuality in fact that law very often has influenced concepts of personal identity. 
Law, in other words, is a component of culture, which in terms of relative priority must precede, not flow from, the existence of the state. This seems clear enough as an historical fact. Even legislation which is the product of a state occupies a place as part of culture and has no meaning or force apart from it. In certain cultures, such as modern Western cultures, law assumes a position of pre-eminence. It need not occupy such pre-eminence in all cultures, and indeed it does not as I have noted above.

Tully acknowledges in fact that legal pluralists are those who have challenged this uniformity supposed to exist in modern states conceived under the dominant rhetoric of modern constitutionalism. It is the rhetoric of modern constitutionalism that devalues alternative conceptions of a state based on principles which acknowledge and respect diversity just as the principles of modernity purport rationally to exclude the likes of custom, tradition and the diversity which this entails both internally and globally. It is modernity and the logic of both universalism and uniformity that drives this rhetoric, which purports in a wider global context to devalue and debase cultural and social diversity.

Furthermore in the Pacific context, it is obvious that the modern constitutional structures which they have adopted assume that law and centralised legal structures can somehow settle the question of identity in some satisfactory way. This, it seems to me, is a dangerous fallacy. It is a question which assumes that more fundamental cultural issues of identity, especially those at the national level, have been settled when in fact they have not. Pacific constitutions, as they presently stand, clearly assume that they have been. However, there is often mere fragmentation and high levels of diversity. The theoretical assumptions are clearly at odds with the reality. Moerover, the expectation that centrally imposed law, in terms of an homogenous central set of legal principles, can formally resolve such issues of identity, especially in societies where there remain deep divisions, and there is little pre-disposition towards law as a means of social ordering, is clearly a pipe dream.

\section{CONCLUSION}

The identity problem is, I think, a crucial one for small South Pacific countries. The orthodox conception of identity to which Tully referred is clearly a colonial legacy. Modern constitutionalism is clearly a major aspect of that legacy; a subsisting residue which has survived independence. It is part and parcel of the attempt to conceive of a state in abstract institutional terms and to position law as a central agency within this perspective. Theoretically it makes a range of assumptions as to uniformity under a coherent body of law, which are clearly at odds with the social and cultural reality of these countries.

The position I have attempted to argue is that the concept of identity which is employed within modern constitutionalism is one which ought to be rethought. In fact it needs to be rethought and reworked in order that these relatively new postindependence countries within the Pacific region can begin seriously to set about a task of nation building which incorporates and makes sense of their unique and 
diverse cultural traditions. Modern constitutional doctrine and the identity principle which goes with it serves, and has served, to exclude cultural diversity. It is only when we understand the identity principle as one of incorporating and preserving diversity, rather than excluding it, that the proper social and cultural dimensions of these constitutional systems can be preserved. The way to do that is, I believe, to understand identity as a contingent principle in the sense in which collective identities emerge as the products of history, rather than as the posulates of abstract philosophical reason. This is essentially what a principle of identity as a 'unity-indiversity' must be taken to imply. Only understood in this way can it capture the historical reality of newly emergent states.

Does that mean that law therefore plays no place in such a scheme of things? I think not. It is fallacy to suggest that law or a legal system necessarily either requires or could achieve the kind of uniformity which many writers seem to assume. Law, surely, is only very loosely a coherent and/or unified system. It is what Stone referred to once as a "complex unity" or a unity which is "multi-fashioned". ${ }^{57}$ It is itself in basic ways a product and sometimes a reflection of historical practices which have preserved within it vital elements of diversity and differentiation, if also at times tension and inconsistency. Thus the identity which law might provide within a state ought to be understood in just this way. 


\section{ENDNOTES}

1 Hooker M.B. 1975. Legal Pluralism: An Introduction to Colonial and Neo-Colonial Laws. Oxford: Clarendon Press at p 6.

2 Griffiths, J. 1986. What is Legal Pluralism? Journal of Legal Pluralism and Unofficial Law 1: 1-56 at p 1. See also Pospisil, L. 1971. Anthropology of Law: A Comparative Theory. New York: Harper and Row. p 1; Van den Bergh, G.C.J.J. 1992. Legal Pluralism in Roman Law. In Verga, C. ed, Comparative Legal Cultures. New York: New York University Press. pp 338-50, p. 451; Galanter, M. 1981. Justice in Many Rooms: Courts, Private Ordering, and Indigenous Law. Journal of Legal Pluralism and Unofficial Law 19: $1-25$ at $\mathrm{p} 1$.

3 Chiba, M. (ed.) 1986. Asian Indigenous Law: An Interaction with Received Law. London and New York: KPI. p 1, 2.

4 See, for example, Llewellyn, K.N. and Hoebel, E.A. 1983. The Cheyenne Way: Conflict and Case Law in Primitive Peoples. Norman: University of Oklahoma Press. 212ff; and Fitzpatrick, P. 1980. Law and State in Papua New Guinea. London: Academic Press. p 100 and 117. Thus legal pluralism rejected the claims made by orthodox legal theorists, as well as by some sociologists or anthropologists in this regard, such as Hobhouse, Pound, Radcliffe-Brown. Hobhouse wrote that "such societies, of course have their customs, which are doubtless felt as binding my their members, but if we mean by law a body of rules enforced by an authority independent of personal ties of kinship and friendship, such an institution is not compatible with their social arrangement." Hobhouse, L.T. 1910. Morals in Evolution. London: Oxford University Press. p 73.

5 Whilst some legal pluralist views might tend to the form of anarchy there does not seem to be a general denial of some role for the state.

6 Not all sovereignty theorists - Austin for example - would agree on this. Austin thought that it was the obedience to a singular individual or body and absence of legal limitation was more important to the concept of sovereignty. Indeed he suggested that the legislative and the executive functions were so confused that one could not really hold out the legislative as that which gave sovereignty or independence to a state. See Rumble, W.E. (ed.) 1995. Austin: The Province of Jurisprudence Determined. Cambridge: Cambridge University Press. p 188, 197.

7 Tie, W. 1999. Legal Pluralism: Toward a Multicultural Conception of Law. Brookfield: Ashgate Publishing Co. at p 177-178. The "diversification of socio-cultural identity within nation-statehood" poses a growing problem for established legal orders which could ultimately bring about "the demise of that whole politico-legal system (and the onset of civil war, for example)."

8 Non-rational, that is, in the post-Enlightenment sense of rationality.

9 See, for example, Austin, above n 6, who refers to natural, "primitive", "domestic" or "savage" societies employing customary law which lacks the "habit of obedience to one and the same superior". Hence they have no law which is enforced by legal and political sanctions. Hence they have no law at all. Rumble, W.E. (ed) 1995. Above, n 6, at p 178. See similarly, Robson, W.A. 1935. Civilisation and the Growth of Law. New York: McMillan. p 7

10 See Surya Prakash Sinha. 1995. Legal Polycentricity. In Petersen H and Zahle H. (eds.) Legal Polycentricity: Consequences of Pluralism in Law. Aldershot: Dartmouth. 31ff. 
11 This is a perspective of law as viewed by non-lawyers.

12 To mention but a few: Griffiths, J. 1986. What Is Legal Pluralism? Journal of Legal Pluralism 1: 1-56; Bohannen, P. Differing Realms of Law. 67 American Anthropologist 65; Pospisil, L. 1958. Kapauku Papuans and Their Law. Yale University Publications in Anthopology 54, 248; Nader, L. 1965. The Anthropological Study of Law. 67 American Anthropologist 3.

13 See Merry, S.E. 1988. Legal Pluralism. Law and Society XXII (5): 869-896 at p. 869. Merry contends that the focus originally was on the role which this dichotomy played in colonised and therefore also post-colonial societies. See also McLennan, G. 1995. Pluralism. Buckingham: Open University Press. Chapter 1.

14 That seems clearly to have been the case with respect to both the Great Council of Chiefs and the Native Lands Trust Board in Fiji, for example.

15 Merry, S.E. 1988. Above, n 13, at p.872; Van den Bergh, G.C.J.J. 1992. Above, n 2, at p 451.

16 Merry, S.E. 1988. Above, n 13, at p 872.

17 Merry, S.E. 1988. Above, n 13, at p 872.

18 And, indeed, the unity of the legal system under the ultimate authority of the state.

19 Baxsi, U. 1986. Discipline, Repression and Legal Pluralism. In Sack, P. and Minschin, E. Legal Pluralism: Proceedings of the Canberra Workshop, Canberra: Australian National University, p 51 .

20 Thus it would meet one of Rohe's criteria for the meaning of politics. It involves discourse about states. It is therefore clear that we can speak of a politics of legal pluralism. See Rohe, K. 1994. Politik: Begriffe und Wirklichkeiten. Stuttgart: Verlag W. Kohlhammer. p 11, 12.

21 See, for example, Griffiths, A.O. 1997. In the Shadow of Marriage: Gender and Justice in an African Community. Chicago: University of Chicago Press. p. 35 and 133. Griffiths argues that this contention need not lead to the conclusion that law permeates the whole social fabric because the distinction between law and non law is socially constituted. (At p 213.)

22 De Lange, R. 1995. Divergence, Fragmentation and Pluralism. In Petersen, H. and Zahle, H. 1995. Above, n 10 at p 105.

23 Hirvonen, A. (ed.) 1988. Polycentricity: The Multiple Scenes of Law. London: Pluto Press. p $1,2$.

24 Chiba, M. 1995. Legal Pluralism in Mind: A Non-Western View. In Petersen, H. and Zahle, H. 1995. Above, n 10 at p 74.

25 Teubner, G. 1997. 'Global Bukowina': Legal Pluralism in World Society. In Teubner G. (ed.) Global Law Without A State. Dartmouth: Aldershot. p 4.

26 Griffiths, J. 1986. Above, n 2 at p 1, 2.

27 Process is also the position adopted by Tie in his attempt to show that legal pluralism can accommodate multicultural ideas.

28 Bergh, G.C.J.J. 1992. Above, n 2, at p 451-454

29 Griffiths, J. 1986. Above, n 2, at p 5.

30 Galanter, M. 1981. Above, n 2, at p 20. Similar points are made by Merry, S.E. 1988. Above n 13; and Pospisil, L. 1971. Above, n 2.

31 Griffiths, J. 1986. Above, n 2, at p 17-18.

32 Of course, it should be noted that this has hardly prevented such states from pushing the idea of legal pluralist systems in their former colonies. 
33 See Sack, P. and Alick, J. 1992. (eds.) Law and Anthropology. Dartmouth: Aldershot. p xviii.

34 See Merry, S.E. 1988. Above, n 13, at p 872; Okotho-Ogendo, H.W.O. 1979. The Imposition of Property Law in Kenya. In Berman, S.S. and Harrell-Bond, B.E. (eds.) The Imposition of Law. New York: Academic Press. p 147-166; Skalnik, P. 1987. On the Inequality of the Concept of the 'Traditional State'. Journal of Legal Pluralism and Unofficial Law 26: 301-321; Geertz, C. 1983. Local Knowledge: Further Essays on Interpretative Anthropology. New York: Basic Books. p 228.

35 See Diamond, S. 1973. The Rule of Law versus the Order of Custom. In Black D. and Mileski M. (eds.) The Social Organisation of Law, New York: Academic Press, pp 318-344, at $\mathrm{p}$ 332. The various views here are discussed in Merry, S.E. 1988. Above, n 13, p 874ff.

36 Although in some respects arguments in this regard are troublesome. The concept of introduced law as simply loa blong weit man is not, given a long period of independence and self determination of many states, quite an accurate description of the situation. Some law might still be introduced law in the strict sense and constitutions might have been modelled on the European model but the characterisation simply as introduced law begs a number of questions.

37 Perhaps there is no need to say that jurisprudence has since moved on from there but this is only a partial truth.

38 We tend to refer to Hobbes as the founder of peculiarly modern ideas in political theory. Perhaps this is an overstatement of his own claims to genius and originality for he draws considerably on a long tradition of thought. That is certainly the case in respect both of his attention to secularism and his use of corporatist principles. The argument on these points is contained in Hughes, R.A. 1995. Identity, Law and Politics. Armidale: UNE Press. Chapter 4.

39 The immediate enemy appeared to be the Cambridge Neoplatonists whose abstruse scholastic doctrines appeared capable of justifying rule by divine right. It is significant that their response to Hobbes was to term his theories 'democritic' a play on Hobbes portrayal of the (human) universe in the State of Nature as behaving much in the fashion of Democritus' dissociated atoms. Hughes, R.A. 1995. Above, n 38, at chapter 4.

40 This reflects Hobbes' distaste for Coke's primacy of judicial reason.

41 Tully, J. 1995. Strange Multiplicities: Constitutionalism in an Age of Diversity. Oxford: Oxford University Press.

42 Tully, J. 1995. Above, n 41, at p 63ff.

43 Tully, J. 1995. Above, n 41 at p 68 Rousseau's conception of the general will appears as a slight variation on Hobbes' notion of personation. About the social contract, he said, "(at) once in place of the individual personality of each contracting party, this act of association creates a corporate and collective body, composed of as many members as the assembly creates voters, and receiving from this act its unity, its common identity, its life, and its will.” Rousseau, J.J. 1975. The Social Contract and Discourses. London: Dent p 175.

44 Tully, J. 1995. Above, n 41, at p 69.

45 Van Trease, H. (ed) 1995. Melanesian Politics: Stael Blong Vanautu. New Zealand: Macmillan Brown Centre for Pacific Studies, University of Canterbury at p 21 
46 The "New Hebridean people" were constructed as singular because of common descent/shared ethnicity.

47 Jowitt, A. 1999. Reconstructing Custom: The Politics of Homophobia in Vanuatu. Unpublished conference paper. $2^{\text {nd }}$ ISSACS Conference, Manchester, July 1999.

48 See, for example, the application of laws provisions in the Constitution of Solomon Islands, section 75 and Schedule 3 which assign customary law to such a subordinate position. See also the decision in To'ofilu v Oimae Unreported, High Court of Solomon Islands, Civil Appeal Case No. 5 of 1996 19th June, 1997.

49 Locke seems to have been the first to employ identity as a concept in relation to a person. It was more usually applied with respect to collective entities some of which were exceedingly general, such as the human species. This redeployment converts it from a universal concept into something particularistic.

50 Hughes, R.A. 1995. Above, n 38. Chapter 4 deals with the political context of the rejection of classical and religious metaphysics in the philosophy of Hobbes, Locke and Hume and the relevance of identity in this context.

51 Hughes, R.A. 1995. Above n 38.

52 See Danielsen D. and Engle K. 1995. After Identity. New York: Routledge, p xiv. This of course hardly prevents the search for new identity concepts or the search for new identities as such.

53 On Hegel's use of identity see Hughes, R. A. 1995. Above, n 38, chapter 5.

54 The dialectical process in Hegel's Philosophy of Right begins specifically with the greatest degree of diversity in human affairs, the individual.

55 All systems are in some basic sense unities in, or of, diversity.

56 Some might prefer the term 'ideology' but culture is more acceptable because ideology has a negative sense in some areas of political theory where the understanding of ideology is itself ideological.

57 Stone, J. 1964. Legal System and Legal Reasoning. London: Stevens and Sons. p 21 and 25 respectively. Such a state of complexity has led Stamford to suggest that the term legal system was itself highly misleading and misrepresentative. In fact he suggests, law is better imagined as "a vast web of relations (or perhaps a multi-dimensional maze)" Stamford, C. 1989. Oxford: Basil Blackwell. p 223. 


\section{Review questions}

1. Identify and discuss restorative justice practices in different parts of the Pacific islands. To what extent do you think that such approaches can be used to reconstitute or stabilise states that are experiencing coups, civil wars or other major social unrest?

2. Are the institutions of the modern state and 'Western' constitutions appropriate or sustainable in the Melanesian states?

3. What are the most important factors and forces at work in your own country which influence the extent to which constitutional limits on the state are accepted by those in power?

4. Consider the extent to which Pacific constitutions assume, or perhaps impose, some underlying principle of identity. Do the assumptions made by the constitutions in this regard, if any, reflect the actual conditions of the society in question?

5. Identity is a principle which seeks to balance out the interests of unity and diversity in a society. Both elements are necessary in any society and neither can be ignored. To what extent does or could law contribute to a solution to this balancing problem?

\section{Further readings}

Dinnen, S. 2001. Law and Order in a Weak State: Crime and Politics in Papua New Guinea Honolulu: University of Hawaii Press.

McLennan, G. 1995. Pluralism. Buckingham: Open University Press.

Moore, S.F. 1978. Law as Process: An Anthropological Approach London, Henley and Boston: Routledge and Kegan Paul.

Petersen, H. and Zahle, H. (eds.) 1995. Legal Polycentricity: Consequences of Pluralism in Law. Aldershot: Dartmouth.

Sack, P. and Minschin, E. 1986. Legal Pluralism: Proceedings of the Canberra Workshop. Canberra: Australian National University.

Tully, J. 1995. Strange Multiplicities: Constitutionalism in an Age of Diversity. Oxford: Oxford University Press.

Weisbrot, D., Paliwala, A. and Sawyer, A. (eds.) 1982. Law and Social Change in Papua New Guinea Sydney: Butterworths. 